\title{
Erythema dyschromicum perstans in a child following an enteroviral meningitis*
}

\author{
Cláudia Raquel Ferrão de Melo ${ }^{1}$ \\ Sónia Carvalho ${ }^{1}$
}

\author{
Mário Correia de Sá ${ }^{2}$
}

DOI: http://dx.doi.org/10.1590/abd1806-4841.201745144

\begin{abstract}
A healthy 6-year-old boy presented with an erythematous macular exanthema, meningeal signs and fever, initially diagnosed with probable bacterial meningitis and treated with antibiotic and anti-inflammatory drugs. Enteroviral meningitis was confirmed, but the skin lesions continued to evolve and the patient was ultimately diagnosed with erythema dyschromicum perstans. The boy was followed during three years until the spontaneous resolution of the dermatosis.
\end{abstract}

Keywords: Hyperpigmentation; Enterovirus; Pediatrics

Erythema dyschromicum perstans (EDP) is an uncommon disease described as asymptomatic eruption of oval, polycyclic, or irregularly shaped, gray-blue hyperpigmented macules on the trunk, arms, face and neck. ${ }^{1}$ Sometimes these macules show erythematous borders. ${ }^{1}$ The etiology of EDP is unclear but an immunologic basis is suspected. There is also a probable genetic susceptibility conferred by genes located within the major histocompatibility complex region. ${ }^{2}$ Histopathological features include dermal perivascular lymphocytic infiltrate with melanophages, vacuolization of the basement membrane zone, necrotic keratinocytes in the basal layer, colloid bodies, exocytosis of lymphocytes, and incontinence of the pigment. ${ }^{3,4}$ Usually, EDP has a chronic but benign course, however most of the cases don't completely resolve. There is no treatment available, though anti-inflammatory topic agents may be effective. ${ }^{1}$ We report a case of a child who developed this condition following an infectious disease, with the rash almost completely resolved after a period of 3 years.

A 6-year-old boy, previously healthy, was admitted to the emergency department with fever, meningeal signs and an erythematous macular rash. Bacterial meningitis was suspected and intravenous antibiotic (ceftriaxone) and anti-inflammatory drugs (ibuprofen) were started. He evolved clinically well, an enterovirus was identified in the liquor and the antibiotic was stopped. Other laboratory results were negative. Two weeks later, the erythematous rash evolved into hyperpigmented, greyish, skin lesions, without desquamation or pruritus. The lesions measured between 0.5 and $3 \mathrm{~cm}$ and some were confluent. The rash affected mainly the neck, trunk and proximal extremities but also the perineum (Figure 1). The mucous membranes, palms, soles and scalp were spared. He had no other symptoms. Histopathological examination of biopsy specimens revealed melanocytic hyperplasia at the basal layer, and dermal perivascular lymphocytic infiltrate with melanophages. A clinical and pathologic diagnosis of EDP was established. Over the following year the number of macules increased and became more visible, however after a period of 3 years of follow-up, the lesions had cleared up almost completely (Figure 2).

EDP, also known as ashy dermatosis, is a rare acquired idiopathic hypermelanosis. The etiology remains unknown, however several predisposing factors have been proposed, such as drugs (antibiotics, benzodiazepines, pesticides), endocrinopathies or infectious disorders such as human immunodeficiency virus infection and hepatitis C.4-6 The main differential diagnosis of EDP is pigmented lichen planus (usually shiny purple, flat-topped, firm papules often crossed by fine white lines) however, lichen planus often involves mucous membranes and is associated with mild pruritus, neither characteristics were present in this boy. Idiopathic eruptive

Received on 16.09.2015

Approved by the Advisory Board and accepted for publication on 05.12.2015

* Study conducted at the Pediatric Department, Centro Hospitalar do Médio Ave - Santo Tirso, Portugal.

Financial Support: None.

Conflict of Interest: None.

Pediatric Department, Centro Hospitalar do Médio Ave, Vila Nova de Famalicão, Portugal.

Pediatric Department, Centro Hospitalar Vila Nova de Gaia/Espinho - Vila Nova de Gaia, Portugal.

C2017 by Anais Brasileiros de Dermatologia 


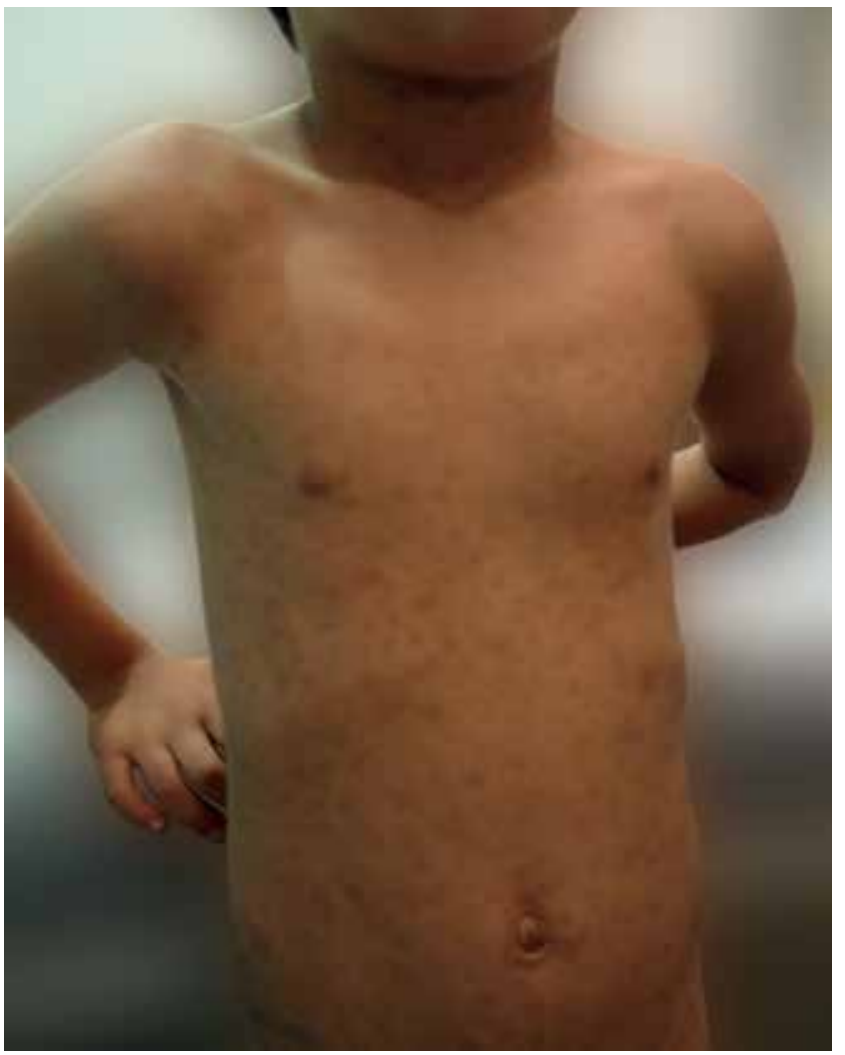

FIGURE 1: Typical grey-coloured hyperpigmented macules

macular pigmentation would be another differential hypothesis, however this condition shows typically with brownish and nonconfluent lesions. ${ }^{3,4}$ In the reported case, EDP was preceded by an enteroviral nervous system infection, so we hypothesize that the infection may have been the trigger for this condition. It seems more probable to be related with the enterovirus infection than related with drugs since the lesions appeared before starting antibiotics and anti-inflammatory drugs. However a conclusive etiology cannot be proven, as usually occurs with EDP. Treatment was not initiated,

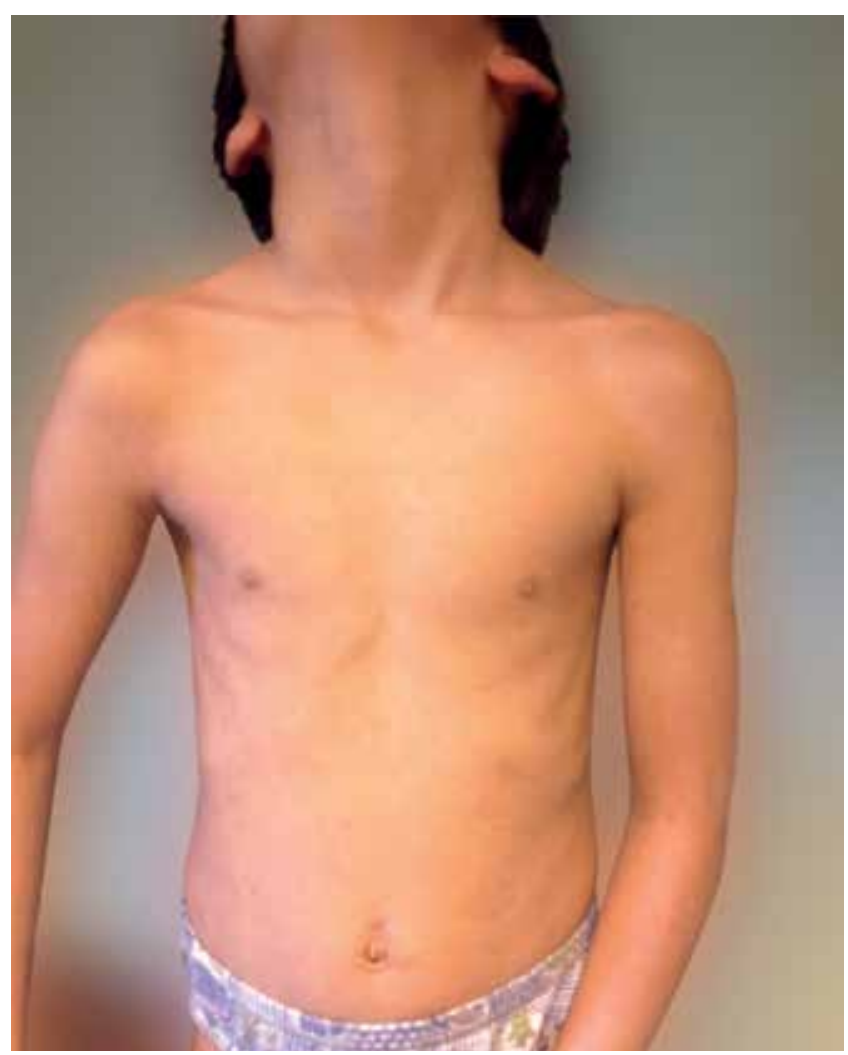

FIGURE 2: Remission of the lesions after a three years period of follow-up

as there was no evidence to support the efficacy of therapy in this condition and it has usually a benign outcome. Our patient gradually improved and achieved almost complete clinical remission after a period of three years. This case illustrates the good prognosis of EDP although with a slow resolution, and also supports possible infectious trigger for this condition. Even considering it as a rare disorder, its early recognition may avoid unnecessary and expensive investigation and therapeutics.]

\section{REFERENCES}

1. Nieuweboer-Krobotova L. Hyperpigmentation: types, diagnostics and targeted treatment options. J Eur Acad Dermatol Venereol. 2013;27:2-4.

2. Correa MC, Memije EV, Vargas-Alarcón G, Guzmán RA, Rosetti F, Acuña-Alonzo $\mathrm{V}$, et al. HLA-DR association with the genetic susceptibility to develop ashy dermatosis in Mexican Mestizo patients. J Am Acad Dermatol. 2007;56:617-20.

3. Oiso N, Tsuruta D, Imanishi H, Kobayashi H, Kawada A. Erythema Dyschromicum Perstans in a Japanese Child. Pediatr Dermatol. 2012;29:637-40.

4. Vásquez-Ochoa LA, Isaza-Guzmán DM, Orozco-Mora B, Restrepo-Molina R, Trujillo-Perez J, Tapia FJ. Immunopathologic study of erythema dyschromicum perstans (ashy dermatosis). Int J Dermatol. 2006;45:937-41.

5. Kontochristopoulos GJ, Aroni K, Anagnostopoulos G, Nakopoulou L, Tassopoulos NC. Erythema dyschromicum perstans and hepatitis $\mathrm{C}$ virus infection. Int J Dermatol. 2001;40:346-8.

6. Cherobin AC, Oliveira FO, Baeta IG, Vale EC. Case for diagnosis. Ashy dermatosis. An Bras Dermatol. 2012;87:151-2.

\author{
MAILING ADDRESS: \\ Cláudia Raquel Ferrão de Melo \\ Rua Cupertino de Miranda \\ Apartado 31 \\ 4761-917 Vila Nova de Famalicão, Portugal. \\ Email: crferrao.melo@gmail.com
}

How to cite this article: Melo CRF, Sá MC, Carvalho S. Erythema dyschromicum perstans in a child following an enteroviral meningitis. An Bras Dermatol. 2017;92(1):137-8. 